\title{
The intersecting-state model: a link between molecular spectroscopy and chemical reactivity
}

\author{
L.G. Arnaut*, A.A.C.C. Pais, S.J. Formosinho ${ }^{1}$ \\ Departamento de Química, Universidade de Coimbra, P-3049 Coimbra Codex, Portugal
}

Received 31 August 2000; accepted 29 September 2000

\begin{abstract}
The intersecting-state model is applied to calculate the energy barriers and rates of atom transfers, $\mathrm{S}_{\mathrm{N}} 2$ reactions, proton transfers and electron transfers, including electron transfer at the metal-electrolyte interface. The calculated rates are usually within one order of magnitude of the experimental ones. These applications of the model reveal the main factors that influence the rates of these chemical reactions. The structural and electronic properties of reactants that are used in the calculations are the reaction energy, the hypervalency at the transition state, the bond lengths and for constants of the reactive bonds. (C) 2001 Elsevier Science B.V. All rights reserved.
\end{abstract}

Keywords: Intersecting-state model; Atom transfer; Methyl transfer; Proton transfer; Electron transfer

\section{Introduction}

Chemists often talk about the "reactivity of a molecule" as if the reactivity was an intrinsic property of that molecule. This simple concept lead to the development of many static reactivity indices that have helped to characterize and classify molecules. Examples of such indices are Hammett constants and electronic densities of frontier orbitals. Chemists know that the encounter of two molecules triggers unique properties that neither molecule possesses alone. But the concept of "reactivity" has been useful to link reaction rates (or activation energies) to molecular structure. Among the best-known examples of struc-

\footnotetext{
* Corresponding author. Tel.: +351-39-822826; fax: +351-39827703.

E-mail address: 1garnaut@ci.uc.pt (L.G. Arnaut).

${ }^{1}$ Universidade Católica Portuguesa, Escola de Ciências e Tecnologia, Viseu, Portugal.
}

ture-kinetics relationships are the postulate of Hammond, linear free-energy relationships (LFER) such as those of Brönsted, Evans-Polanyi, Hammett and Tafel, and Marcus cross-relation. These relationships helped to shape physical-organic chemistry and still play an important role in our understanding of "families" of reactions.

A more rigorous approach evolved from the field of theoretical chemistry. A major breakthrough was the formulation of the transition-state theory (TST), because it related the reaction rate with the structure of activated complexes and reactants. This theory has been fully exploited in recent years with the availability of rigorous potential energy surfaces for some tri and tetra-atomic systems, that are obtained from analytical fits to the results of very sophisticated $a b$ initio calculations. A better understanding of the link between molecular structure can be achieved by combining the qualitative insight of structurekinetics relationships with the quantitative approach 
Table 1

Morse curve parameters employed in ISM calculations. All data were calculated by the PM3 method, except where indicated

\begin{tabular}{|c|c|c|c|}
\hline Molecule & $\begin{array}{l}D_{298} \\
\left(\mathrm{~kJ} \mathrm{~mol}^{-1}\right)\end{array}$ & $\begin{array}{l}\beta(\text { for } \mathrm{H}-\mathrm{X}) \\
\text { or } \omega(\text { for } \mathrm{X}- \\
\mathrm{C})\left(\AA^{-1} \text { or }\right. \\
\left.\mathrm{cm}^{-1}\right)\end{array}$ & $l_{\mathrm{eq}}(\AA)$ \\
\hline $\mathrm{H}_{2}{ }^{\mathrm{a}}$ & 457.3 & 1.939 & 0.741 \\
\hline $\mathrm{HF}^{\mathrm{a}}$ & 589.1 & 2.222 & 0.917 \\
\hline $\mathrm{HCl}^{\mathrm{a}}$ & 445.2 & 1.872 & 1.275 \\
\hline $\mathrm{HBr}^{\mathrm{a}}$ & 378.2 & 1.819 & 1.415 \\
\hline $\mathrm{H}_{2} \mathrm{O}^{\mathrm{a}}$ & 516.3 & 2.200 & 0.960 \\
\hline $\mathrm{NH}_{3}{ }^{a}$ & 466.1 & 2.181 & 1.012 \\
\hline $\mathrm{CH}_{4}{ }^{\mathrm{a}}$ & 453.1 & 1.947 & 1.087 \\
\hline $\mathrm{SiH}_{4}{ }^{\mathrm{a}}$ & 392.5 & 1.521 & 1.480 \\
\hline $\mathrm{C}_{2} \mathrm{H}_{6}{ }^{\mathrm{a}}$ & 434.7 & 1.962 & 1.094 \\
\hline $\mathrm{CH}_{3} \mathrm{CH}_{2} \mathrm{SH}^{\mathrm{a}}$ & 379.1 & 1.851 & 1.350 \\
\hline $\mathrm{CH}_{3}-\mathrm{CH}_{2} \mathrm{CH}_{3}$ & $368^{\mathrm{b}}$ & $1054^{\mathrm{b}}$ & 1.512 \\
\hline $\mathrm{CH}_{3}-\mathrm{SiH}_{2} \mathrm{CH}_{3}$ & $368^{\mathrm{c}}$ & $770^{\mathrm{d}}$ & 1.873 \\
\hline $\mathrm{CH}_{3}-\mathbf{G e H}_{2} \mathrm{CH}_{3}$ & 314 & 651 & 1.957 \\
\hline $\mathrm{CH}_{3}-\mathbf{S n H}_{2} \mathrm{CH}_{3}$ & 205 & 541 & 2.177 \\
\hline $\mathrm{CH}_{3}-\mathrm{NHCH}_{3}$ & 259 & 1143 & 1.474 \\
\hline $\mathrm{CH}_{3}-\mathbf{P H C H}_{3}$ & 264 & 664 & 1.868 \\
\hline $\mathrm{CH}_{3}-\mathrm{AsHCH}_{3}$ & 234 & 607 & 1.973 \\
\hline $\mathrm{CH}_{3}-\mathrm{SbHCH}_{3}$ & 201 & 597 & 2.162 \\
\hline $\mathrm{CH}_{3}-\mathrm{OCH}_{3}$ & 276 & $1014^{\mathrm{b}}$ & 1.405 \\
\hline $\mathrm{CH}_{3}-\mathrm{SCH}_{3}$ & 280 & 723 & 1.801 \\
\hline $\mathrm{CH}_{3}-\mathrm{SeCH}_{3}$ & 280 & 648 & 1.948 \\
\hline $\mathrm{CH}_{3}-\mathbf{T e C H} \mathrm{H}_{3}$ & 146 & 470 & 2.200 \\
\hline $\mathbf{F}-\mathrm{CH}_{3}$ & $452^{\mathrm{b}}$ & $1049^{b}$ & 1.351 \\
\hline Cl- $-\mathrm{CH}_{3}$ & $347^{\mathrm{b}}$ & $732^{\mathrm{b}}$ & 1.764 \\
\hline $\mathrm{Br}-\mathrm{CH}_{3}$ & $293^{\mathrm{b}}$ & $611^{\mathrm{b}}$ & 1.951 \\
\hline I- $\mathrm{CH}_{3}$ & $234^{\mathrm{b}}$ & $533^{b}$ & 2.027 \\
\hline
\end{tabular}

${ }^{a}$ From Ref. [3].

b From the compilation in Ref. [47].

c From Ref. [49].

${ }^{\mathrm{d}}$ From similar compounds in Ref. [48].

of theoretical chemistry. In this work we describe some advancements along these lines made possible by the application of the intersecting-state model (ISM) to atom transfers, nucleophilic substitutions, proton transfers (PT) and electron transfers (ET).

\section{The ISM}

A reaction path for the prototypical reaction

$\mathrm{A}+\mathrm{BC} \rightarrow \mathrm{AB}+\mathrm{C}$

can be obtained using Morse curves to describe the reactant and product bonds

$V_{\mathrm{BC}}=D_{\mathrm{BC}}\left\{1-\exp \left[-\beta_{\mathrm{BC}}\left(l-l_{\mathrm{BC}}\right)\right]\right\}^{2}$

$V_{\mathrm{AB}}=D_{\mathrm{AB}}\left\{1-\exp \left[-\beta_{\mathrm{AB}}\left(l-l_{\mathrm{AB}}\right)\right]\right\}^{2}+\Delta V^{0}$

where $D_{\mathrm{BC}}\left(D_{\mathrm{AB}}\right)$ is the bond dissociation energy and $\beta_{\mathrm{BC}}\left(\beta_{\mathrm{AB}}\right)$ the Morse parameter of the $\mathrm{BC}(\mathrm{AB})$ bond, and from the relation

$l_{\mathrm{BC}}^{\ddagger}-l_{\mathrm{BC}}=-a^{\prime}\left(l_{\mathrm{BC}}+l_{\mathrm{AB}}\right) \ln \left(n_{\mathrm{BC}}^{\ddagger}\right)$

$l_{\mathrm{AB}}^{\ddagger}-l_{\mathrm{AB}}=-a^{\prime}\left(l_{\mathrm{BC}}+l_{\mathrm{AB}}\right) \ln \left(n_{\mathrm{AB}}^{\ddagger}\right)$

where $l_{\mathrm{BC}}\left(l_{\mathrm{AB}}\right)$ is the equilibrium and $l_{\mathrm{BC}}^{+}\left(l_{\mathrm{AB}}^{+}\right)$the transition state (TS) bond length of the $\mathrm{BC}(\mathrm{AB})$ bond, $n_{\mathrm{BC}}$ $\left(n_{\mathrm{AB}}^{+}\right)$its bond orders at the TS and $a^{\prime}$ a scaling constant, provided that the bond order is conserved along the reaction coordinate $\left(n=n_{\mathrm{AB}}=1-n_{\mathrm{BC}}\right)$. This conservation of the bond order follows closely that formulated in the bond-energy-bond-order model [1], and the relation between bond lengths and bond orders is similar to that expressed by Pauling [2]. This reaction coordinate can be expressed as the sum of bond extensions of reactants and products

$d^{\ddagger}=\left|l_{\mathrm{BC}}^{\ddagger}-l_{\mathrm{BC}}\right|+\left|l_{\mathrm{AB}}^{\ddagger}-l_{\mathrm{AB}}\right|$

The substitution of Eq. (2) in Eq. (1) to obtain the TS energies, $V_{\mathrm{BC}}^{+}$and $V_{\mathrm{AB}}^{+}$, followed by the premise that at the TS $V_{\mathrm{BC}}^{\ddagger}=V_{\mathrm{AB}}^{\ddagger}$, offers a simple method to determine the energy barrier of an atom-transfer reaction. When TS features electronic interactions that are not found in the reactants, it may be necessary to allow for a smoother or steeper dependence of the bond length on its bond order. ISM introduces a parameter $m$ that admits values larger than unity for TS with enhanced electronic resonance. This parameter is interpreted as an increase in bond order at TS, and is related to the electronic structure of the reactants. Taken these interactions into account, the energy of TS is determined by the value of $n$ that satisfies the equality [3]

$D_{\mathrm{BC}}\left[1-\exp \left(\frac{a^{\prime}\left(l_{\mathrm{BC}}+l_{\mathrm{AB}}\right)}{m} \beta_{\mathrm{BC}} \ln (1-n)\right)\right]^{2}$

$=D_{\mathrm{AB}}\left[1-\exp \left(\frac{a^{\prime}\left(l_{\mathrm{BC}}+l_{\mathrm{AB}}\right)}{m} \beta_{\mathrm{AB}} \ln (n)\right)\right]^{2}+\Delta V^{0}$ 
Table 2

Structural properties and rates of selected gas-phase hydrogen atom abstractions

\begin{tabular}{|c|c|c|c|c|c|}
\hline Reaction & $\Delta H^{\mathrm{a}}\left(\mathrm{kJ} \mathrm{mol}{ }^{-1}\right)$ & $l_{\mathrm{AB}}+l_{\mathrm{Bc}}{ }^{\mathrm{a}}(\AA)$ & $f_{\mathrm{BC}}{ }^{\mathrm{a}}\left(\mathrm{kJ} \mathrm{mol}^{-1} \AA^{-2}\right)$ & $f_{\mathrm{AB}}{ }^{\mathrm{a}}\left(\mathrm{kJ} \mathrm{mol}^{-1} \AA^{-2}\right)$ & $E_{\mathrm{a}}{ }^{\mathrm{b}}$ \\
\hline (I) $\mathrm{H}+\mathrm{H}_{2} \rightarrow \mathrm{H}_{2}+\mathrm{H}$ & 0 & 1.482 & 3439 & 3439 & 32 \\
\hline (II) $\mathrm{CH}_{3}+\mathrm{CH}_{4} \rightarrow \mathrm{CH}_{4}+\mathrm{CH}_{3}$ & 0 & 2.174 & 3435 & 3435 & 61 \\
\hline (III) $\mathrm{C}_{2} \mathrm{H}_{5}+\mathrm{C}_{2} \mathrm{H}_{6}$ & 0 & 2.188 & 3348 & 3348 & 56 \\
\hline \multicolumn{6}{|l|}{$\rightarrow \mathrm{C}_{2} \mathrm{H}_{6}+\mathrm{C}_{2} \mathrm{H}_{5}$} \\
\hline (IV) $\mathrm{CH}_{3}+\mathrm{C}_{2} \mathrm{H}_{6} \rightarrow \mathrm{CH}_{4}+\mathrm{C}_{2} \mathrm{H}_{5}$ & -19 & 2.181 & 3348 & 3435 & 48 \\
\hline (V) $\mathrm{Cl}+\mathrm{H}_{2} \rightarrow \mathrm{HCl}+\mathrm{H}$ & +12 & 2.016 & 3439 & 3120 & 21 \\
\hline
\end{tabular}

${ }^{\text {a }}$ From Table 1.

${ }^{\mathrm{b}}$ References in the text.

The calculation of the TS energy requires the knowledge of the scaling factor $a^{\prime}$, which is obtained from a reference system. A very convenient reference system is the $\mathrm{H}+\mathrm{H}_{2}$ reaction. Its experimental activation energy $\left(E_{\mathrm{a}}=31.8 \mathrm{~kJ} \mathrm{~mol}^{-1}\right)[4]$ is reproduced when $a^{\prime}=0.157$ and $m=1$, given the Morse curve parameters of the $\mathrm{H}-\mathrm{H}$ bond, Table 1 . In fact, a different procedure was used to scale ISM in its original formulation, and $a^{\prime}=0.156$ was obtained. For consistency with earlier applications of ISM we continue to use $a^{\prime}=0.156$. The difference between the two scaling procedures is negligible. This scaling incorporates the normal electronic resonance effect in the energy barriers. The data needed to calculate the energy barriers of the atom (and methyl) transfers addressed in this work are shown in Table 1.

Now that we showed how to calculate activation energies, we can calculate classical rates with the conventional TST

$k=s \kappa \frac{\mathrm{k}_{\mathrm{B}} T}{h} \frac{N_{\mathrm{A}} q_{\ddagger}^{\phi}}{q_{\mathrm{A}}^{\phi} q_{\mathrm{BC}}^{\phi}} \exp \left(-\frac{E_{0}}{\mathrm{R} T}\right)$

where $s$ is a statistical factor, $\kappa$ a transmission coefficient usually assumed to be close to unity, $q_{\mathrm{A}}^{\phi}, q_{\mathrm{BC}}^{\phi}$ and $q_{\ddagger}^{\phi}$ the standard molecular partition-functions of the reactants and TS, $E_{0}$ the difference in energy between the initial substances and the activated complex at the absolute zero, and the other symbols have their usual meaning. $E_{0}$ is not the same as the barrier calculated by ISM, $\Delta V^{\ddagger}$, that we have associated with the activation energy $E_{\mathrm{a}}$. Rather, in the gas phase we have

$E_{0}=\Delta V^{\ddagger}+0.5 \mathrm{R} T$
The rigorous application of TST requires the knowledge of the symmetric stretching and bending frequencies of TS. This cannot be obtained by onedimensional models. It is possible to incorporate more or less sophisticated methods to account for these frequencies but, for the sake of simplicity, we will simply assume that the ratio of the vibrational partition functions is close to unity. This approximation looses its validity for very high temperatures. Within this approximation and assuming that TS is linear, Eq. (5) can be simplified to give

$$
\begin{aligned}
k_{\mathrm{c}}= & s \frac{6.82 \times 10^{10}}{\sqrt{T}}\left(\frac{m_{\mathrm{A}}+m_{\mathrm{B}}+m_{\mathrm{C}}}{m_{\mathrm{A}}\left(m_{\mathrm{B}}+m_{\mathrm{C}}\right)}\right)^{3 / 2} \\
& \times \frac{I_{\mathrm{ABC}}}{I_{\mathrm{BC}}} \exp \left(-\frac{E_{0}}{\mathrm{R} T}\right) \mathrm{dm}^{3} \mathrm{~mol}^{-1} \mathrm{~s}^{-1}
\end{aligned}
$$

when the masses are expressed in atomic mass units and the moments of inertia $I_{\mathrm{ABC}}$ and $I_{\mathrm{BC}}$ are calculated with the bond lengths employed by ISM, Eq. (2). For simplicity, in polyatomic systems the masses $m_{\mathrm{A}}$ and $m_{\mathrm{C}}$ can be taken as the sum of the masses of the atoms that make the fragments $\mathrm{A}$ and $\mathrm{C}$, respectively.

Eq. (7) does not include tunneling corrections. They may substantially increase the rates at low temperatures. For example, the rate of the $\mathrm{H}+\mathrm{H}_{2}$ atom transfer increases by a factor of 7 at $300 \mathrm{~K}$ [5]. However, the scaling with an experimental activation energies in the $450-750 \mathrm{~K}$ temperature range implicitly takes tunneling into account in this temperature range. Thus, we expect that this classical version of ISM will be particularly suited to calculate $k$ in the $300-1000 \mathrm{~K}$ temperature range in good agreement with the experimental ones. 


\section{Atom-transfer reactions}

Table 2 presents gas-phase $\mathrm{H}$-abstractions, selected to illustrate how subtle changes in the molecular structure of the reactants may induce significantly different reaction rates. Our goal is to relate the changes in rate with those in molecular structure using ISM. Reactions (I) and (II) are symmetrical $\left(\Delta E^{0}=0\right)$ and the reactive bonds have similar force constants

$f_{\mathrm{BC}}=2 D_{\mathrm{BC}}\left(\beta_{\mathrm{BC}}\right)^{2}$

but the bond lengths of the first are much shorter than those of the second. The consequences of this difference are illustrated in Fig. 1A. The larger value of $d^{\ddagger}$ of reaction (II) is responsible for its much higher activation energy. We calculate $\Delta V^{\ddagger}=$ $32.6 \mathrm{~kJ} \mathrm{~mol}^{-1}$ for reaction (I) with the scaling factor $a^{\prime}=0.156$ chosen to reproduce its experimental activation energy, and for reaction (II) we calculate $\Delta V^{\ddagger}=61.1 \mathrm{~kJ} \mathrm{~mol}^{-1}$ that should be compared with $E_{\mathrm{a}}=61.1 \mathrm{~kJ} \mathrm{~mol}^{-1}[6]$.

Reaction (III) is also a symmetrical reaction and involves the breaking of bonds with lengths very similar to those of reaction (II). There is a $3 \%$ difference in their force constants. According to Fig. 1B, a lower force constant should lead to a decrease in activation energy. We calculate $\Delta V^{\ddagger}=59.9$ $\mathrm{kJ} \mathrm{mol}^{-1}$ and the experimental value is $E_{\mathrm{a}}=$ $55.6 \mathrm{~kJ} \mathrm{~mol}^{-1}$ [6].

Reaction (IV) is an exothermic reaction. Otherwise, it involves structural parameters that closely resemble those of reaction (III). It is known that the rates of related reactions tend to increase with exothermicity. The decrease in $E_{\mathrm{a}}$ is illustrated in Fig. 1C, which also reveals that ISM is consistent with Hammond's postulate [7] and the Evans-Polanyi relationship [8]

$E_{\mathrm{a}}=E_{0}+\alpha \Delta H^{0}$

where $E_{0}$ and $\alpha$ are constants. In a more quantitative basis, the energy barrier of reaction (IV) is predicted to be $52 \mathrm{~kJ} \mathrm{~mol}^{-1}$, and the experimental value is $E_{\mathrm{a}}=$ $48 \mathrm{~kJ} \mathrm{~mol}^{-1}$.

Finally, reaction $(\mathrm{V})$ involves the attack of a $\mathrm{Cl}$ atom, rather than an alkyl radical. The comparison between the structural and thermodynamic properties of reactions (I) and (V) suggests that the latter should be slower. However, in previous applications of ISM it was shown that in TS of reaction
(V), nonbonded electrons of $\mathrm{Cl}$ may contribute to the bonding at TS and lead to an "increased bond order" $m=2$ [3,9]. Fig. 1D shows the effect of increased bond order, or increased electronic resonance relative to the reference reaction, in the energy of the TS. This can either be seen as a smoother dependence of the energy on the bond extension, translated by the division of the exponential factors of Eq. (1) by $m=2$, or as smaller bond extension, given by the division of $d^{\dagger}$ by $m=2$.

The classical rate constants calculated by our formalism are in good agreement with the experimental data collected in the 300-1000 K temperature range. This is illustrated in Fig. 2 using the $\mathrm{CH}_{3}+\mathrm{C}_{2} \mathrm{H}_{6} \rightarrow \mathrm{CH}_{4}+\mathrm{C}_{2} \mathrm{H}_{5}$ reaction, which has been the subject of numerous experimental studies [10]. It is expected that the approximations involved in Eq. (7) will not be valid for complex systems, with entropic restrictions.

The value $m=2$ also applies to symmetrical atom transfers (AT) between atoms with nonbonded electrons, as shown in Table 3. It is obvious that intermediate values of $m$ can be found for atom transfers between carbon or hydrogen atoms and atoms with nonbonded electrons. Fig. 3 shows that in such cases the intermediate values of $m$ can be correlated with the electron affinity of the reaction partner.

\section{Nucleophilic substitutions}

In a recent communication $\mathrm{Hoz}$ et al. [11] calculated the intrinsic barriers of identity $\mathrm{S}_{\mathrm{N}} 2$

Table 3

Calculated and experimental activation-energies, $E_{\mathrm{a}}$, of symmetric atom exchanges involving atoms with nonbonded electrons $(m=2)$

\begin{tabular}{llcl}
\hline System & $\Delta V^{\ddagger}(\mathrm{kJ} / \mathrm{mol})$ & $E_{\mathrm{a}}(\mathrm{kJ} / \mathrm{mol})$ & References \\
\hline $\mathrm{HO}+\mathrm{HOH}$ & 21.5 & 17.6 & {$[50]$} \\
$\mathrm{Cl}+\mathrm{HCl}$ & 23.0 & 25 & {$[51]$} \\
$\mathrm{CH}_{3} \mathrm{CH}_{2} \mathrm{~S}+\mathrm{HSCH}_{2} \mathrm{CH}_{3}$ & 21.3 & 21.7 & {$[51]$} \\
$\mathrm{HCl}+\mathrm{D}$ & 23.0 & $12-34$ & {$[52]$} \\
$\mathrm{HBr}+\mathrm{D}$ & 22.3 & 20 & {$[52]$} \\
\hline
\end{tabular}



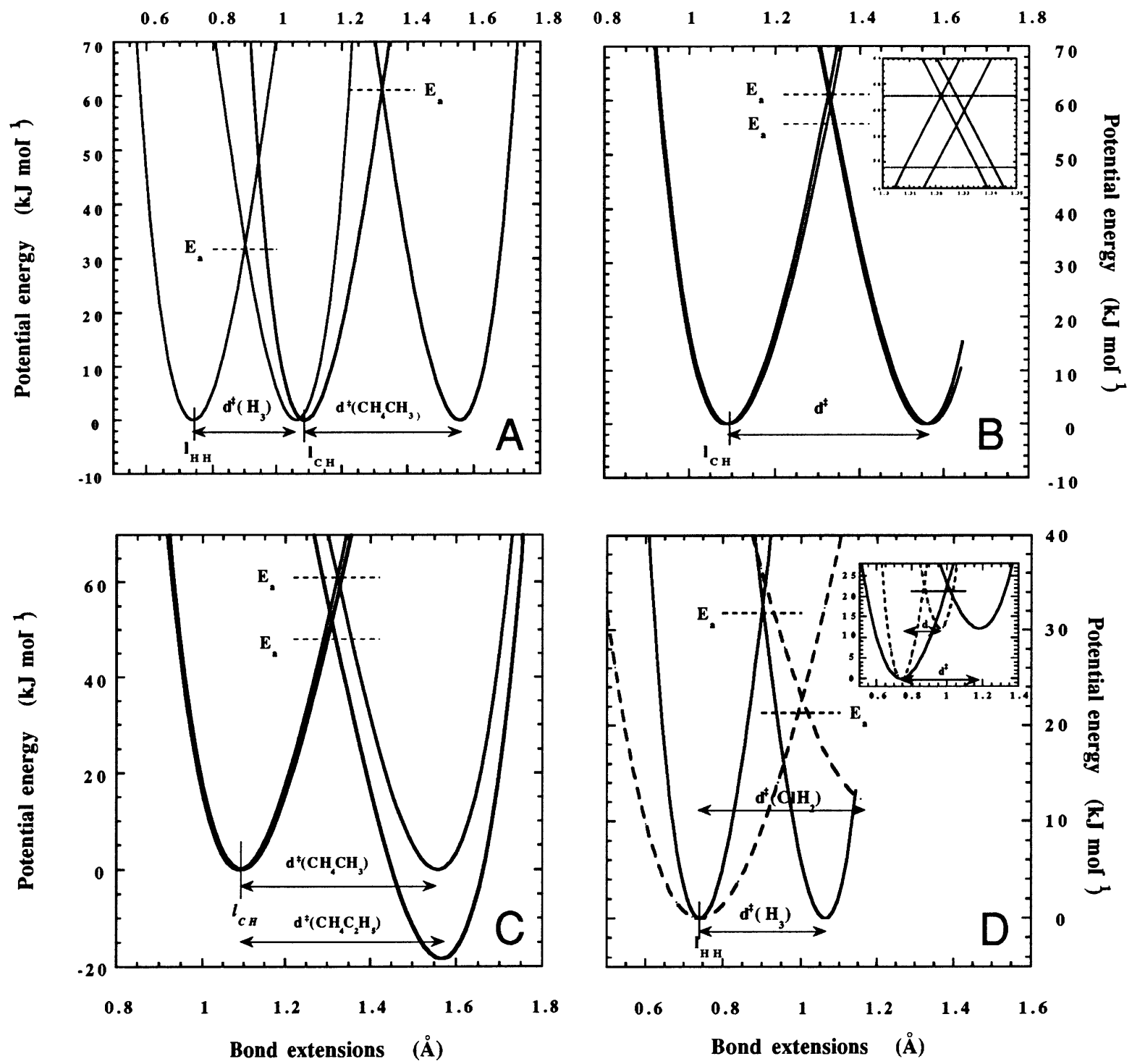

Fig. 1. Reaction coordinate of atom-transfer reactions according to ISM. The dashed horizontal lines indicate the experimental activation energies $\left(E_{\mathrm{a}}\right.$ ). (A) $\mathrm{H}+\mathrm{H}_{2}$ vs $\mathrm{CH}_{3}+\mathrm{CH}_{4}$; (B) $\mathrm{CH}_{3}+\mathrm{CH}_{4}$ vs $\mathrm{C}_{2} \mathrm{H}_{5}+\mathrm{C}_{2} \mathrm{H}_{6}$ (lower force constant, lower energy barrier and lower $E_{\mathrm{a}}$ ); $(\mathrm{C}$ ) $\mathrm{CH}_{3}+\mathrm{CH}_{4} \mathrm{vs}_{2} \mathrm{H}_{5}+\mathrm{CH}_{4}$; (D) $\mathrm{H}+\mathrm{H}_{2}$ vs $\mathrm{Cl}+\mathrm{H}_{2}$ (the inset shows that dividing the exponential factors of Eq. (1) by $m=2$ gives the same barrier as dividing $d^{\ddagger}$ by $m=2$ ).

reactions

$$
\begin{aligned}
& { }^{*} \mathrm{X}^{-}+\mathrm{CH}_{3} \mathrm{X} \rightarrow{ }^{*} \mathrm{X}^{-} \cdots \mathrm{CH}_{3} \mathrm{X} \rightarrow{ }^{*} \mathrm{XCH}_{3} \cdots \mathrm{X}^{-} \\
& \rightarrow{ }^{*} \mathrm{XCH}_{3}+\mathrm{X}^{-}
\end{aligned}
$$

where ${ }^{*} \mathrm{X}$ is an isotopically labeled atom. They considered $\mathrm{X}$ to be $\mathrm{CH}_{3}-\mathrm{CH}_{2}\left(-\mathrm{SiH}_{2},-\mathrm{GeH}_{2}\right.$, -
$\left.\mathrm{SnH}_{2}\right), \mathrm{CH}_{3}-\mathrm{NH}(-\mathrm{PH},-\mathrm{AsH},-\mathrm{SbH}), \mathrm{CH}_{3}-\mathrm{O}(-$ $\mathrm{S},-\mathrm{Se},-\mathrm{Te})$, and $\mathrm{F}(\mathrm{Cl}, \mathrm{Br}, \mathrm{I})$ in the sixteen systems examined. The geometries and energies of the reactant, complex and TS where obtained $a b$ initio through the $\mathrm{G} 2(+)$ method [11]. Their main conclusion is that the intrinsic barrier, $\Delta E_{0}^{\ddagger}$, is largely determined by the valence of $\mathrm{X}$, which 


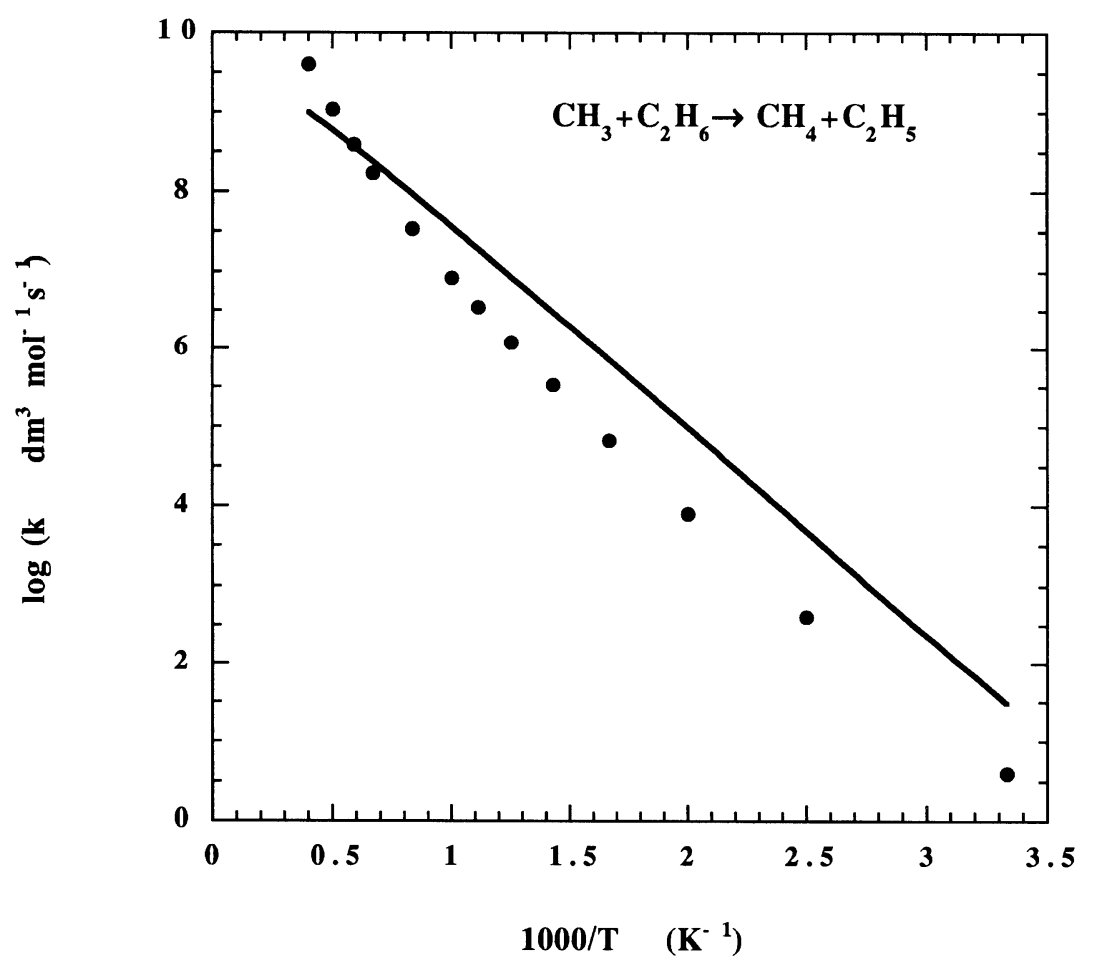

Fig. 2. Calculated $m=1$ and recommended rate constants for the $\mathrm{CH}_{3}+\mathrm{C}_{2} \mathrm{H}_{6}$ reaction [10].

corresponds to a definite placement of the element $\mathrm{X}$ in the periodic table. However, they were unable to offer any explanation for the trends of this intrinsic barrier.

A curve-crossing model for the bond-breakingbond-forming process in reaction (II), in which a $\mathrm{CH}_{3}$ transfer occurs concomitantly with an ET, provides a simple way to predict and rationalize the arising complex dissociation barriers. We will discuss these barriers, again resorting to ISM, based on previous application to other exchange reactions [3].

The application of ISM to reaction (II) implies the knowledge of the Morse curve for each of the $\mathrm{X}-\mathrm{CH}_{3}$ system. Due to the variety of elements considered, we have chosen to use theoretically calculated bond stretching constants and bond strengths in most systems (except where reliable experimental information is available), employing the semiempirical PM3 method via the GAMESS package [12], and also theoretical PM3 equilibrium distances for all systems. This choice was prompted by: (i) the computationally inexpensive nature of this method; (ii) the relatively accu- rate frequencies and geometrical parameters it provides; and (iii) the fact that the model is not strongly dependent on the bond strengths for identity reactions, thus forgiving some less adequately calculated formation enthalpies. We additionally stress that only reactant and product molecules involving the bond being broken and formed have to be considered, and that all the respective $\mathrm{X}-\mathrm{CH}_{3}$ equilibrium distances thus derived are essentially coincident with those found in the reactant complex by the $\mathrm{G} 2(+)$ method.

The input data for ISM and respective source are summarized in Table 1. Additionally, the bond order at TS is set by Eq. (4). We performed some preliminary calculations with $m=1$ for $\mathrm{X}$ involving $\mathrm{C}$ to Sn, thus ignoring minor differences in these systems [3], $m=1.33$ for $\mathrm{N}$ to Te, and $m=2$ for $\mathrm{F}-\mathrm{I}$, as in previous work for atom transfers [3]. The results obtained yielded barriers and distensions from the complex to the TS that are too low in comparison to those obtained with the probably accurate $\mathrm{G} 2(+)$ method. The above bond orders were then scaled by 


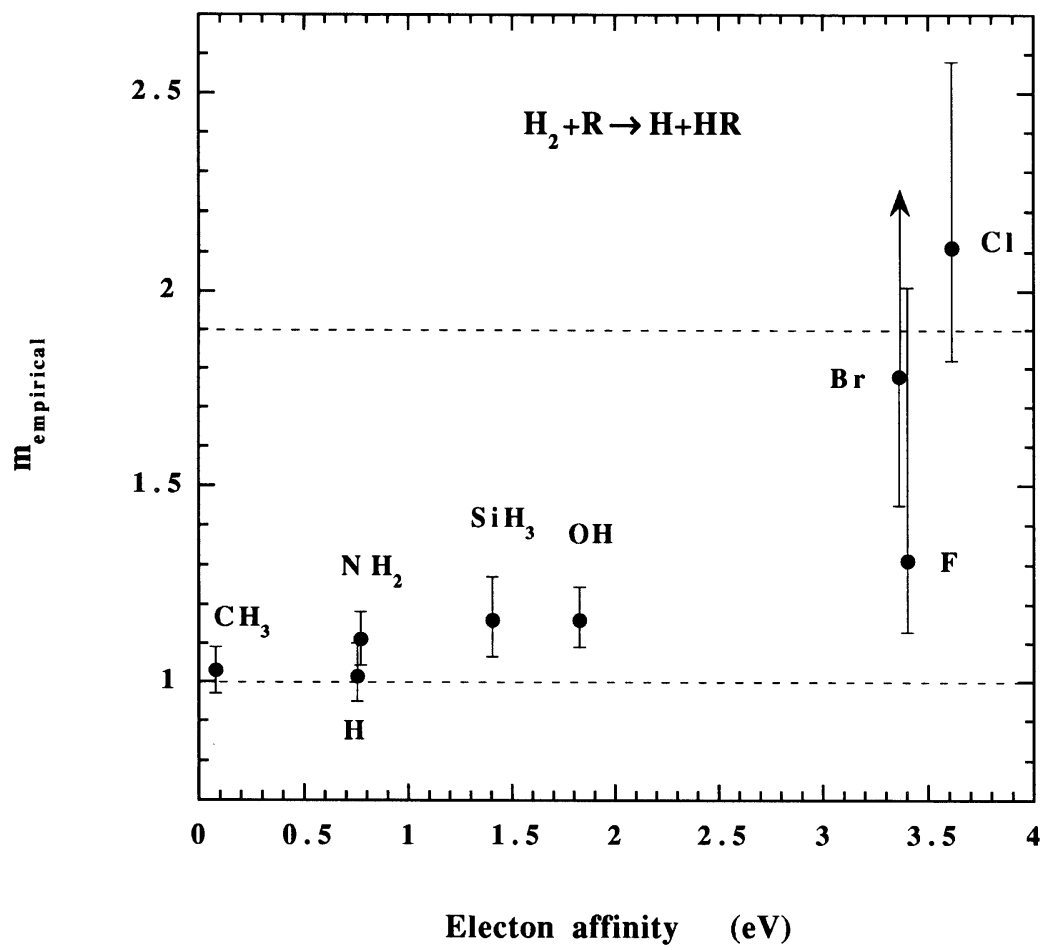

Fig. 3. Correlation between the values of $m$ that reproduce the experimental activation energies $\left(E_{\mathrm{a}}\right)$ of $\mathrm{R}+\mathrm{H}_{2}$ atom transfers and the electron affinities of $\mathrm{R}$. The $E_{\mathrm{a}}$ of $\mathrm{R}=\mathrm{CH}_{3}, \mathrm{NH}_{2}, \mathrm{OH}$ and $\mathrm{F}$ are from Ref. [62], $\mathrm{R}=\mathrm{SiH}_{3}$ from Ref. [63] and $\mathrm{R}=\mathrm{Br}$ from Ref. [64]. The $E_{\mathrm{a}}$ values of $\mathrm{R}=\mathrm{H}$ and $\mathrm{Cl}$ are given in the text.

a constant factor of approximately 0.75 . This factor can be rationalized by the fact that the central $\mathrm{CH}_{3}$ group in TS prevents preservation of the bond order due to steric effects and implies a raise in the intrinsic barrier due to its planarization from the approximately tetrahedral geometry in the reactant species.

The results obtained with ISM for the intrinsic barrier are summarized in Table 4 . The main differences between our results and the $\mathrm{G} 2(+)$ can be found in the carbon group, for $\mathrm{C}$ and $\mathrm{Si}$. However, our values for the former are in excellent agreement with RRKM calculations on the same system. For the nitrogen group, barriers also tend to be slightly lower than those estimated from $\mathrm{G} 2(+)$. We recall that, in the present form, ISM is calibrated for the prediction of $E_{\mathrm{a}}$ rather than energy barriers. In spite of these differences, the overall picture remains the same and the periodical behavior can be found employing both approaches.

In our view, the intrinsic barriers are determined by
Table 4

Calculated intrinsic barriers, in $\mathrm{kJ} \mathrm{mol}^{-1}$, for step 2 of reaction (II). Only the elements in bold in Table 1 are indicated. The first line for each element corresponds to ISM values, the second to G2(+) results [11] and the third and fourth to RRKM and the ShaikPross SCD model, respectively [53]. For chlorine an additional value (experimental-RRKM) was introduced [54]

\begin{tabular}{lllllllll}
\hline $\mathbf{C}$ & 155 & $\mathbf{N}$ & 105 & $\mathbf{O}$ & 105 & $\mathbf{F}$ & 46 & ISM \\
& 188 & & 121 & & 84 & & 50 & G2(+) \\
& 155 & & & & 100 & & - & RRKM \\
& 197 & & & & 88 & & 50 & SCD \\
& & & & & & & & \\
Si & 146 & P & 75 & S & 92 & Cl & 46 & ISM \\
& 192 & & 125 & & 92 & & 54 & G2(+) \\
& & & & & 105 & & 42 & RRKM \\
& & & & & 67 & & 25 & SCD \\
& & & & & & & 56.9 & $($ exp. $)$ \\
Ge & 126 & As & 75 & Se & 84 & Br & 42 & ISM \\
& 159 & & 105 & & 75 & & 46 & G2(+) \\
& & & & & & & 46 & RRKM \\
Sn & 100 & Sb & 79 & Te & 54 & I & 38 & ISM \\
& 130 & & 84 & & 63 & & 42 & G2(+) \\
\hline
\end{tabular}


the same factors as the AT reactions: the equilibrium distances and force constants of the bonds being formed and broken, and hipervalency effects at TS. It is therefore extremely simple to rationalize the intrinsic barrier values and the periodic behavior. As we ascend in atomic number in each group, the force constant of the bond decreases, which would lead to a decrease in the barrier height, partially compensated by an increase in the equilibrium bond distances that lead to increased distensions. The predicted variations within the group are therefore relatively small. When we ascend in the row, the number of nonbonding electrons capable of participating in an increased valence TS structure also increases. Barrier heights thus reduce along the row, in spite of the minor alterations in the equilibrium distances or force constants.

\section{5. $\mathrm{PT}$ reactions}

The transfer of a proton from an acid to a base

$$
\mathrm{AH}+\mathrm{B}^{-} \underset{k_{\mathrm{d}}}{\stackrel{k_{\mathrm{p}}}{\rightleftarrows}} \mathrm{A}^{-}+\mathrm{HB}
$$

is closely related with the bond-breaking-bondforming reactions discussed above. However, the breaking of the $\mathrm{AH}$ and $\mathrm{BH}$ bonds is not homolytic, and the dissociation energies used in Morse curves are not applicable. For simplicity, we represent $\mathrm{AH}$ and $\mathrm{BH}$ bonds by harmonic oscillators with force constants and bond lengths characteristic of bonds involved in the PT reaction: $f_{\mathrm{OH}}=4.2 \times 10^{3}, f_{\mathrm{NH}}=$ $3.8 \times 10^{3}, f_{\mathrm{CH}}=2.9 \times 10^{3} \mathrm{~kJ} \mathrm{~mol}^{-1} \AA^{-2}$, and $l_{\mathrm{OH}}=$ 0.97 ( 0.958 for water), $l_{\mathrm{NH}}=1.01, l_{\mathrm{CH}}=1.07 \AA$ [13]. Within this approximation, $\Delta G^{\ddagger}$ of a PT can be estimated from an expression analogous to Eq. (4), replacing Morse by harmonic oscillators. The PT rates are given by the usual transition-state expression [14-17]

$k_{\mathrm{pt}}=\frac{\mathrm{k}_{\mathrm{B}} T}{h} C^{1-b} \exp \left(-\frac{\Delta G^{\ddagger}}{\mathrm{R} T}\right)$

where $C=1 M$ is the standard concentration and $b=$ 2 is the molecularity of the reaction. The change to $\Delta G$ is consistent with the estimate of the free energy of the reaction from the acidity constants of $\mathrm{AH}$ and
$\mathrm{BH}$

$\Delta G^{0}=-2.303 \mathrm{R} T\left(\mathrm{p} K_{\mathrm{BH}}-\mathrm{p} K_{\mathrm{AH}}\right)$

Statistical corrections accounting for the number of equivalent acidic protons and basic sites are applied whenever necessary.

Table 5 collects results obtained for symmetrical PT reactions. This table also includes the deprotonation of toluene by lithium cyclohexylamide in cyclohexylamine, because the statistically corrected $\mathrm{p} K_{\mathrm{a}}$ values of toluene and of the solvent are very close (41.2 and 41.6, respectively) [18], and their proton exchange can be calculated as if they were symmetrical. The agreement with experimental rates is encouraging, given the simplicity of the model.

The effect of the free-energy in the PT rates can also be assessed using the procedure indicated for the AT rates. The protonation of acetate ion by a series of oxygen acids in aqueous solutions of ionic strength $1 \mathrm{M}$ and at $T=293 \mathrm{~K}$ [19] can exemplify this procedure,

$\mathrm{CH}_{3} \mathrm{COO}^{-}+\mathrm{HA} \rightarrow \mathrm{CH}_{3} \mathrm{COOH}+\mathrm{A}^{-}$

Such series of reactions are usually interpreted in terms of the Brönsted relation,

$k_{\mathrm{p}}=G_{\mathrm{p}}\left(K_{\mathrm{HA}}\right)^{\alpha}$

and, in fact, the statistically corrected experimental $k_{\mathrm{p}}$ follow this LFER with $\alpha=0.53$. These PTs occur between two $\mathrm{O}$ atoms and the ISM rates must be calculated with $m=2$. The comparison between experimental and calculated rates is shown in Fig. 4. The Brönsted coefficient calculated by ISM is $\alpha=$ 0.52 . Such results suggest that $\log k_{\mathrm{p}}$ has a quadratic (rather than linear) dependence on $\Delta G^{0}$, but a wider range of $\Delta G^{0}$ is necessary to test this prediction. The $k_{\mathrm{p}}$ of ketonization of enolates reported by Wirz [20] cover an extraordinary range of free-energies and

Table 5

Proton exchange rates $\mathrm{k} / \mathrm{m}^{-1} \mathrm{~s}^{-1}$ in water at $298 \mathrm{~K}$, except for toluene, which is in cyclohexylamine

\begin{tabular}{lllll}
\hline System & $m$ & $k_{\text {ISM }}$ & $k_{\text {exp }}$ & References \\
\hline $\mathrm{C}_{6} \mathrm{H}_{5} \mathrm{CH}_{3}+\mathrm{LiCHA}$ & 1 & 0.15 & 0.10 & {$[55]$} \\
$\mathrm{NH}_{4}^{+}+\mathrm{NH}_{3}$ & 2 & $6.6 \times 10^{8}$ & $3.2 \times 10^{8}$ & {$[56]$} \\
$\mathrm{OH}^{-}+\mathrm{H}_{2} \mathrm{O}$ & 2 & $7.0 \times 10^{8}$ & $1.7 \times 10^{9}$ & {$[57]$} \\
$\mathrm{H}_{3} \mathrm{O}^{+}+\mathrm{H}_{2} \mathrm{O}$ & 2 & $7.0 \times 10^{8}$ & $3.3 \times 10^{9}$ & {$[57]$} \\
\hline
\end{tabular}




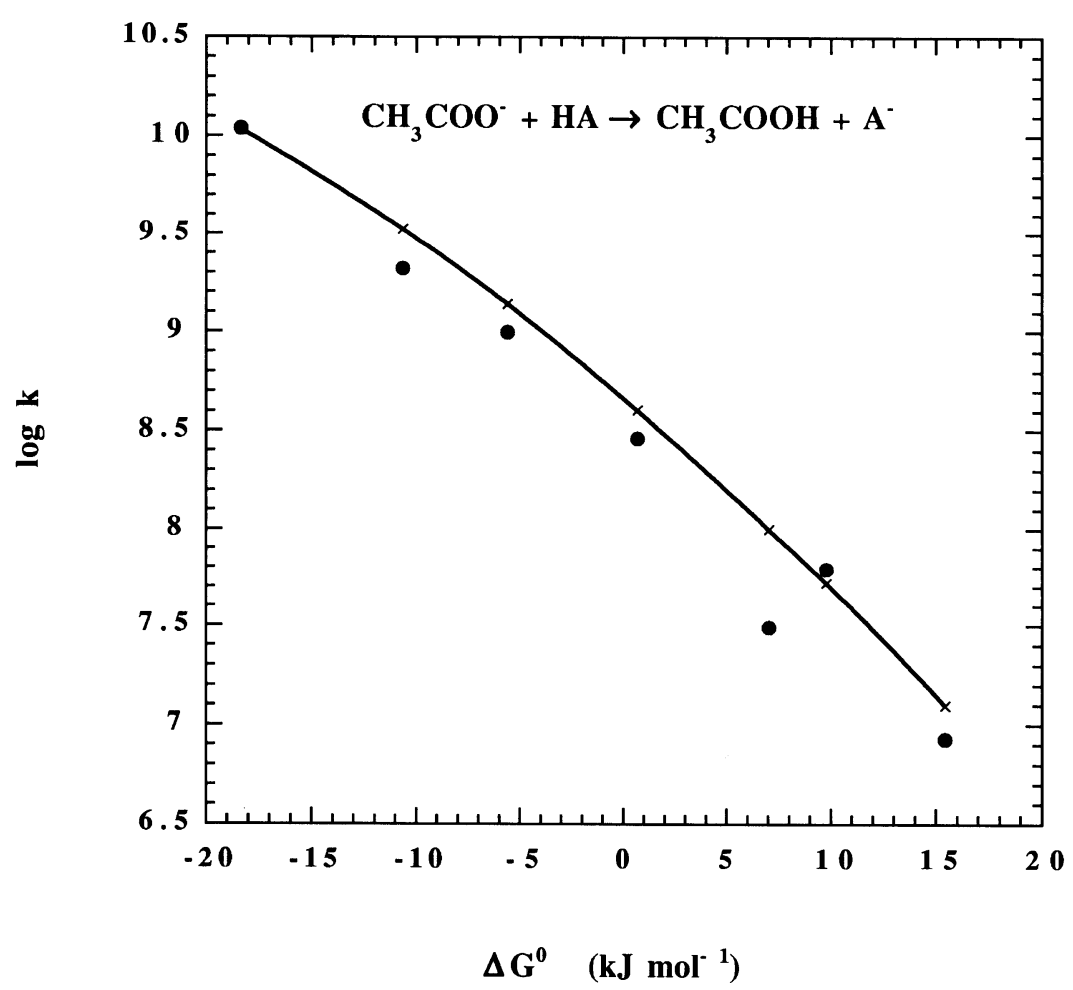

Fig. 4. Calculated and experimental rate constants for the protonation of acetate ion in aqueous solution [19]. $\mathrm{AH}=\mathrm{KH}_{2} \mathrm{PO}_{4},\left(\mathrm{CH}_{3}\right)_{2} \mathrm{As}(\mathrm{O}) \mathrm{OH}$, $\mathrm{HO}_{2} \mathrm{CCH}_{2} \mathrm{CO}_{2} \mathrm{H}, \mathrm{CH}_{3} \mathrm{CH}_{2} \mathrm{CO}_{2} \mathrm{H}, \mathrm{ClCH}_{2} \mathrm{CO}_{2} \mathrm{H}, \mathrm{Cl}_{2} \mathrm{CHCO}_{2}$.

rates constants and reveal the quadratic dependence discussed above. Such dependence is usually interpreted in terms of the Marcus expression for PT [21]

$k_{\mathrm{M}}=k_{\mathrm{diff}} \exp \left(-\frac{\Delta G^{\ddagger}}{\mathrm{R} T}\right)$

where

$\Delta G^{\ddagger}=\Delta G_{0}^{\ddagger}\left(1+\frac{\Delta G^{0}}{4 \Delta G_{0}^{\ddagger}}\right)^{2}$

Wirz fitted rates presented in Fig. 5 with $k_{\text {diff }}=1 \times$ $10^{11} \mathrm{M}^{-1} \mathrm{~s}^{-1}$ and an "intrinsic barrier" $\Delta G_{0}^{\ddagger}=$ $57 \mathrm{~kJ} \mathrm{~mol}^{-1}$ [20]. In order to calculate these rates with ISM, we need to estimate the value of $m$. Adding the difference between the LOMO energies of acetone and $\mathrm{CH}_{2}=\mathrm{C}(\mathrm{OH}) \mathrm{CH}_{3}$ to the electron affinity $\left(A_{\mathrm{e}}\right)$ of acetone, we obtain $A_{\mathrm{e}}=1.35 \mathrm{eV}$ for the enol. As seen in Fig. 3 this corresponds to $m=1.2$. Fig. 5 shows that the calculated rates are in excellent agreement with the experimental ones and follow the quadratic dependence.

According to Marcus cross-relation, the quadratic dependence observed when the rates are measured over a large range of $\Delta G^{0}$ results from the use of intersecting harmonic oscillators to represent reactants and products. This is not entirely accurate because the separation between the equilibrium position of reactant and product oscillators increases with the exothermicity of the reactions, Fig. 6 . The dependence of $d$ on $\Delta G^{0}$ is obtained explicitly when the reaction coordinate is written in terms of an intrinsic and a thermodynamic contribution $[22,23]$

$$
G(n)=[-(1-n) \ln (1-n)-n \ln (n)] \frac{\Lambda}{\sqrt{m}}+n \Delta G^{0}
$$

The parameter $\Lambda$ ensures the equivalence between 


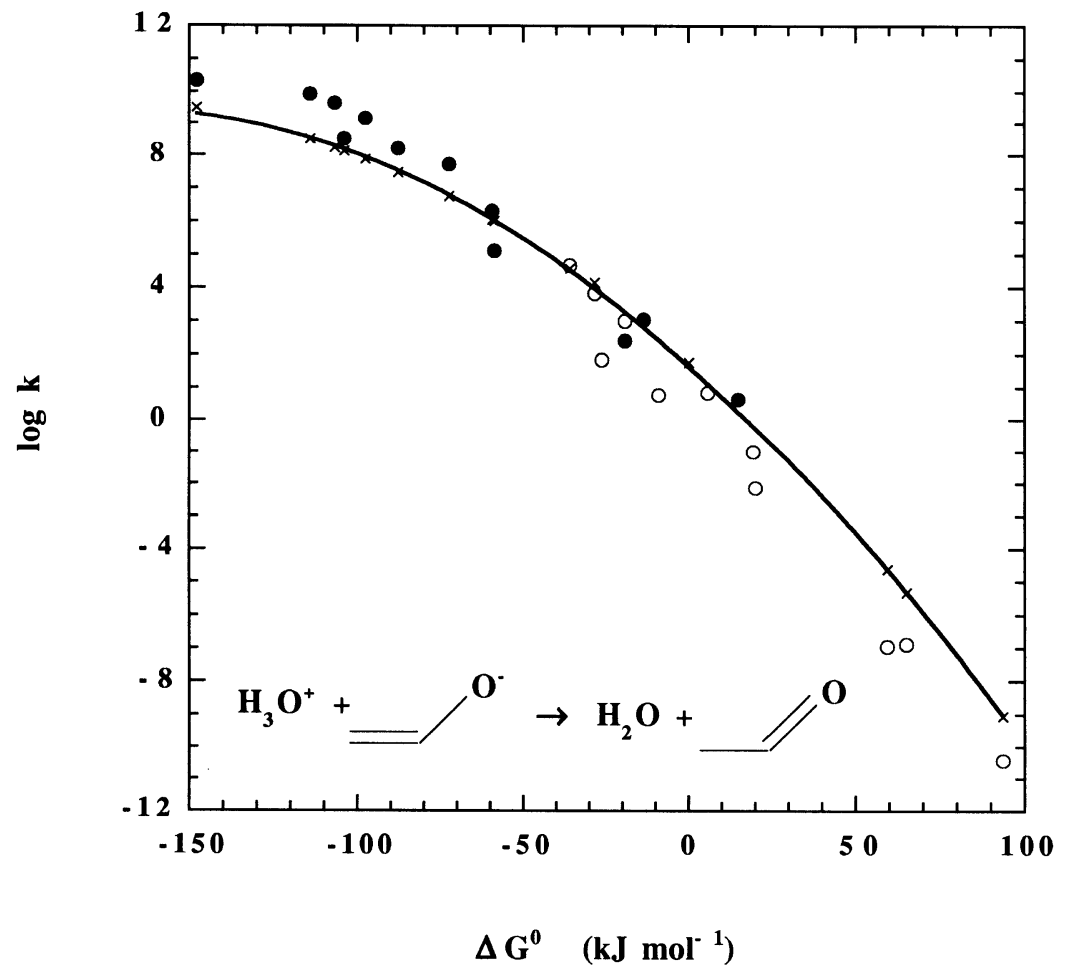

Fig. 5. Calculated and experimental rate constants for the ketonization of enolates [20].

the two formulations of ISM. It has energy units and behaves as an intrinsic barrier, as shown by the case of a symmetric reaction $\left(\Delta G^{0}=0, n^{\ddagger}=0.5\right)$ represented by harmonic oscillators,

$$
\Lambda_{0}=\frac{\sqrt{m} \Delta^{\ddagger} G}{\ln (2)}=\frac{f_{\mathrm{BC}}+f_{\mathrm{AB}}}{2} \frac{\left(l_{\mathrm{BC}}+l_{\mathrm{AB}}\right)^{2}}{m^{3 / 2}}\left(a^{\prime}\right)^{2} \ln (2)
$$

Deriving this reaction coordinate and equating to zero we obtain the TS bond order, $n^{\ddagger}$. If we then apply the conservation of the bond order and use Eqs. (2) and (3), we obtain $[9,24]$

$$
\begin{aligned}
d= & \frac{a^{\prime}\left(l_{\mathrm{AB}}+l_{\mathrm{BC}}\right)}{m} \\
& \times \ln \frac{\left[1+\exp \left(-\sqrt{m} \frac{\Delta G^{0}}{\Lambda}\right)\right]}{\left\{1-\left[1+\exp \left(-\sqrt{m} \frac{\Delta G^{0}}{\Lambda}\right)\right]^{-1}\right\}}
\end{aligned}
$$

with $m=2 n^{\ddagger}$. Eq. (17) shows that $d$ increases with $\left|\Delta G^{0}\right|$ and this increase is modulated by $\Lambda$.

The formulation of ISM with explicit separation of intrinsic and thermodynamic contributions to the reaction coordinate is particularly useful to understand the effect of nonreactive modes. They were neglected in the precedent analysis, which focused only on the reactive bonds. For example, the rates of reversible deprotonation of acetylacetone were measured in carboxylate buffers in $\mathrm{Me}_{2} \mathrm{SO}$-water mixtures, and it was shown that the curvature of corresponding Brönsted plots increases with the $\mathrm{Me}_{2} \mathrm{SO}$ content of the solvent [25]. We calculate these rates with $m=$ 1.20 in water, $m=1.23$ in $50 \% \mathrm{Me}_{2} \mathrm{SO}-50 \%$ water (v/v), $m=1.30$ in $90 \% \mathrm{Me}_{2} \mathrm{SO}-10 \%$ water, and $m=$ 1.33 in $95 \% \mathrm{Me}_{2} \mathrm{SO}-5 \%$ water using the procedure described for the other PT reactions. Fig. 7 shows that calculated and experimental rates of weakly endothermic reactions are in good agreement. The small increase in $m$ as the solvent polarity decreases reflects the greater availability of the electronic 


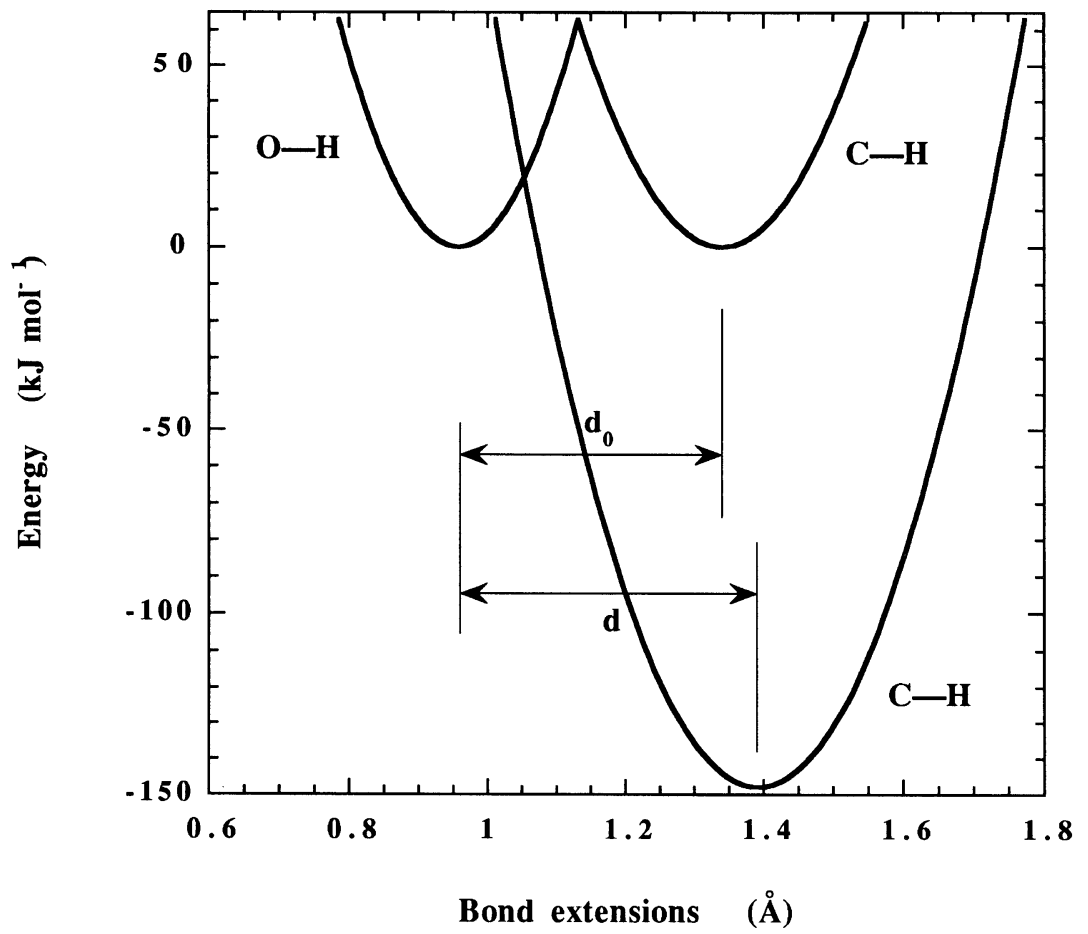

Fig. 6. Reaction coordinate for the ketonization of enolates showing the increase in $d$ with $\left|\Delta G^{0}\right|$.

charges to increase bonding at TS. However, the calculated rates tend to deviate from the experimental ones as $\Delta G^{0}$ departs from zero. On the other hand, we can use Eq. (17) and fit $\Lambda$ to reproduce the experimental rates in each solvent mixture. This is also shown in Fig. 7. The values obtained are, in $\mathrm{kJ} \mathrm{mol}^{-1}, \Lambda=250$ in water, $\Lambda=140$ in $50 \%$ $\mathrm{Me}_{2} \mathrm{SO}-50 \%$ water (v/v), $\Lambda=80$ in $90 \% \mathrm{Me}_{2} \mathrm{SO}-$ $10 \%$ water, and $\Lambda=75$ in $95 \% \mathrm{Me}_{2} \mathrm{SO}-5 \%$ water. The values obtained by the nonparametric version of ISM are $100<\Lambda<125 \mathrm{~kJ} \mathrm{~mol}^{-1}$. The observation of slightly lower $\Lambda$ values in apolar solvents and higher $\Lambda$ values in polar solvents is general for PT reactions. Our view is that polar solvents couple better to the PT reaction and efficiently dissipate its energy, leading to a smaller increase of $d$ with $\Delta G^{0}$ and, therefore, to a higher $\Lambda$.

\section{ET reactions}

ET reactions are one of the most fundamental processes in Chemistry and Biology. They are seemingly unrelated with the bond-breaking-bondforming reactions discussed above, because the reactive bonds preserve their integrity along the reaction coordinate. For this reason, ET reactions have been interpreted in terms of the theory originally proposed by Marcus [26], which treats the solvent as a dielectric continuum. According to Marcus theory (MT), the reorganization energy of an ET reaction has a contribution due to the solvent reorganization, that for spherical reactants of similar radii $r$ can be written

$\Delta G_{\mathrm{out}}^{*}=\frac{e^{2}}{4}\left(\frac{1}{2 r}\right)\left(\frac{1}{n_{\mathrm{D}}^{2}}-\frac{1}{\epsilon}\right)$

where $n_{\mathrm{D}}$ and $\epsilon$ are the refractive index and static dielectric constant of the solvent, and a contribution from the changes in the $i$-bond-lengths of the reactants

$\Delta G_{\text {in }}^{*}=\sum_{i} \frac{f_{i}^{\text {ox }} f_{i}^{\text {red }}\left(l_{i}^{\text {ox }}-l_{i}^{\text {red }}\right)^{2}}{2\left(f_{i}^{\text {ox }}+f_{i}^{\text {red }}\right)}$

where $l_{\text {ox }}\left(l_{\text {red }}\right)$ and $f_{\text {ox }}\left(f_{\text {red }}\right)$ are the equilibrium bond 


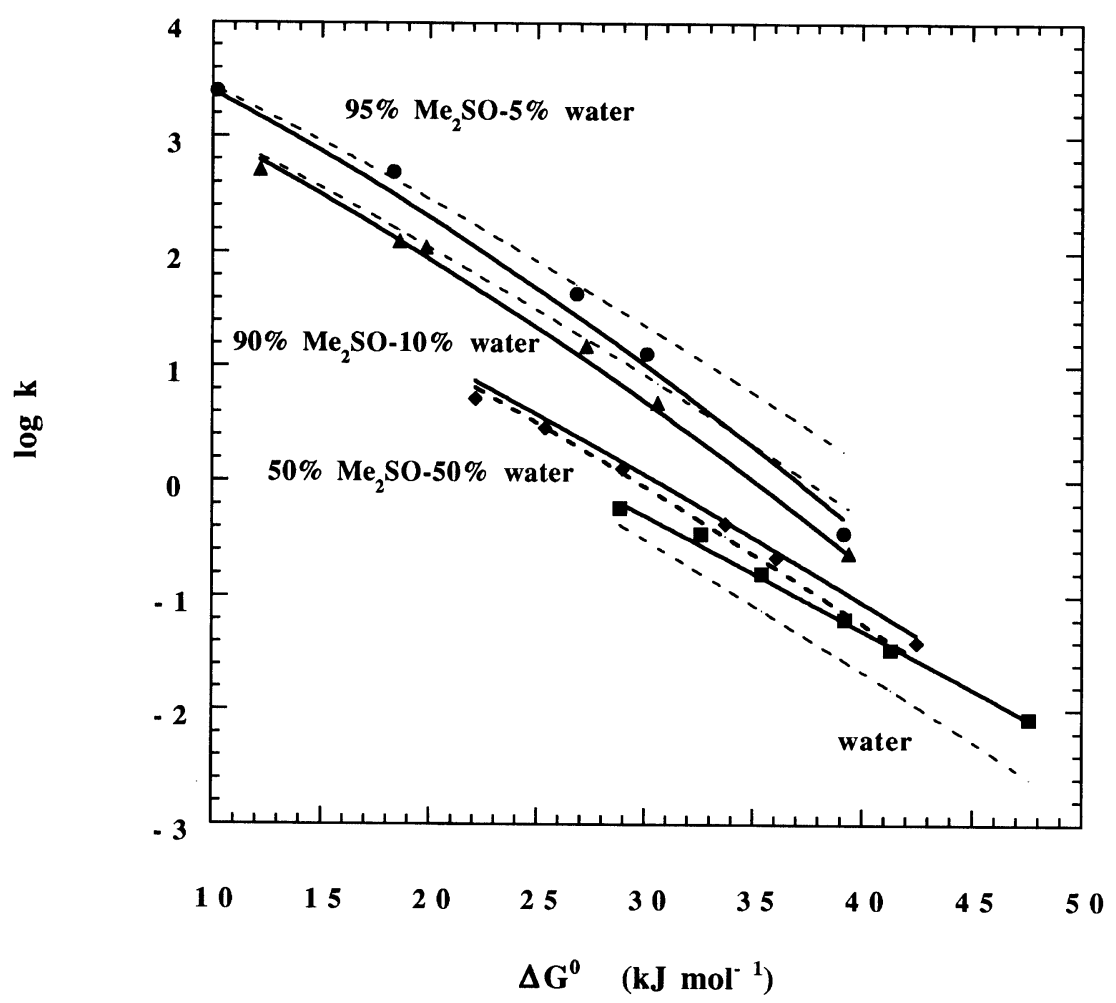

Fig. 7. Solvent effects in the deprotonation of acetylacetone by carboxylate buffers [25]. The dashed lines are nonparametric calculations with ISM and the full lines were calculated with Eq. (17) fitting to reproduce the experimental free-energy dependence of the rates. Nonparametric and parametric calculations employed the same values of $m$.

lengths and force constants of the oxidized (reduced) species, respectively.

These equations predict that the electron selfexchange rate of $\mathrm{O}_{2} / \mathrm{O}_{2}^{-}$in water, of naphthalene/ naphthalene ${ }^{--}$in acetonitrile and of $\mathrm{C}_{60} / \mathrm{C}_{60}^{--}$in less polar solvents should have successive large accelerations. At room temperature, the self-exchange rate of $\mathrm{O}_{2} / \mathrm{O}_{2}^{--}$in water is $450 \mathrm{M}^{-1} \mathrm{~s}^{-1}$ [27], that of naphthalene/naphthalene ${ }^{--}$in acetonitrile is $6.2 \times$ $10^{8} \mathrm{M}^{-1} \mathrm{~s}^{-1}$ [28] and that of the tert-butyl- $\mathrm{C}_{60}$ radical adduct and $t$ - $\mathrm{BuC}_{60}^{-}$in benzonitrile/benzene $(1: 7 \mathrm{v} / \mathrm{v})$ is $1.9 \times 10^{8} \mathrm{M}^{-1} \mathrm{~s}^{-1}$ [29]. Eq. (19) gives $\Delta G_{\mathrm{in}}^{*}\left(\mathrm{C}_{60} /\right.$ $\left.\mathrm{C}_{60}^{\cdot-}\right) \approx 0, \quad \Delta G_{\text {in }}^{*}$ (naphthalene/naphthalene $\left.{ }^{\cdot-}\right) \approx 6.7$ $\mathrm{kJ} \mathrm{mol}^{-1}$ [30], and we calculate $\Delta G_{\mathrm{in}}^{*}\left(\mathrm{O}_{2} / \mathrm{O}_{2}^{-}\right)=$ $17.5 \mathrm{~kJ} \mathrm{~mol}^{-1}$ with $l_{\text {ox }}=1.207\left(l_{\text {red }}=1.33\right) \AA$ and $f_{\text {ox }}=7.09 \times 10^{3}\left(f_{\text {red }}=3.42 \times 10^{3}\right) \mathrm{kJ} \mathrm{mol}^{-1} \AA^{-2}$ for $\mathrm{O}_{2}\left(\mathrm{O}_{2}^{--}\right)$. The solvent reorganization energies can be calculated with $r=1.33 \AA$ for $\mathrm{O}_{2}^{-}$[31], $r=3.67 \AA$ for naphthalene/naphthalene ${ }^{\cdot-}$ and $r=5.60 \AA$ for $\mathrm{C}_{60}$, based on their molar volumes. With these values we obtain $\Delta G_{\text {out }}^{*}=71.8 \mathrm{~kJ} \mathrm{~mol}^{-1}$ for $\mathrm{O}_{2} / \mathrm{O}_{2}^{--}$in water, $\Delta G_{\text {out }}^{*}=21.9 \mathrm{~kJ} \mathrm{~mol}^{-1}$ for naphthalene/naphthalene ${ }^{\cdot-}$ in acetonitrile and $\Delta G_{\text {out }}^{*} \approx 10 \mathrm{~kJ} \mathrm{~mol}^{-1}$ for $\mathrm{C}_{60} / \mathrm{C}_{60}^{--}$in benzonitrile/benzene $(1: 7 \mathrm{v} / \mathrm{v})$ assuming that this medium has an effective dielectric constant of 5. The difference of reorganization energies leads to the prediction that the ratios of these self-exchange rates should be $1: 2 \times 10^{3}: 8 \times 10^{13}$ whereas the experimental ratios are 1:0.3:4 $\times 10^{5}$. This discrepancy reveals that MT does not reflect the structure-reactivity relationships that may exist in ET reactions. It has also been shown that the self-exchange rates are only weakly dependent of the solvent polarity [32].

The application of ISM to ET reactions

$$
\operatorname{Red}_{1}+\mathrm{Ox}_{2} \rightarrow \mathrm{Ox}_{1}+\operatorname{Red}_{2}
$$

(charges omitted) must take into account the fact that species 1 and 2 must be represented by harmonic 
Table 6

Electron self-exchanges of organic species and ferrocene (In acetonitrile or $N, N$-dimethylformamide (DMF) solution, at 293 or $298 \mathrm{~K}$; TCNQ $=7,7,8,8$-tetracyano- $p$-quinodimethane, TMPPD $=N, N, N^{\prime}, N^{\prime}$-tetramethyl- $p$-phenylenediamine, PPD $=p$-phenylenediamine, All the calculated rates were corrected for diffusion with $k_{\text {diff }}=1.9 \times 10^{10} \mathrm{M}^{-1} \mathrm{~s}^{-1}$ in acetonitrile and $k_{\text {diff }}=8.5 \times 10^{9} \mathrm{M}^{-1} \mathrm{~s}^{-1}$ in DMF. Except where noted, the references to the original experimental data can be found in Ref. [32])

\begin{tabular}{|c|c|c|c|c|c|c|c|}
\hline \multirow[t]{2}{*}{ Reactants } & \multirow[t]{2}{*}{$n^{\ddagger \mathrm{a}}$} & \multicolumn{2}{|c|}{ Bond lenghts $^{\mathrm{b}}(\AA)$} & \multicolumn{2}{|l|}{ Force constants ${ }^{\mathrm{b}}$} & \multirow{2}{*}{$\begin{array}{l}\text { ISM } \\
k_{\mathrm{ISM}}\left(\mathrm{M}^{-1} \mathrm{~s}^{-1}\right)\end{array}$} & \multirow{2}{*}{$\begin{array}{l}\text { Experimental } \\
k_{\text {exp }}\left(\mathrm{M}^{-1} \mathrm{~s}^{-1}\right)\end{array}$} \\
\hline & & $l_{\mathrm{ox}}$ & $l_{\text {red }}$ & $f_{\mathrm{ox}}\left(\mathrm{kJ} \mathrm{mol}^{-1} \mathrm{~A}^{-2}\right)$ & $f_{\text {red }}\left(\mathrm{kJ} \mathrm{mol}^{-1} \mathrm{~A}^{-2}\right)$ & & \\
\hline Naphthalene $^{0 /-}$ & 1.43 & 1.398 & & 3810 & & $1.3 \times 10^{9}$ & $6.2 \times 10^{8}$ \\
\hline Anthracene $e^{0 /-}$ & 1.42 & 1.406 & & 3770 & & $1.4 \times 10^{9}$ & $4.8 \times 10^{8}$ \\
\hline $\mathrm{C}_{60}^{0 /-\mathrm{c}}$ & 1.33 & 1.435 & & & & $9.9 \times 10^{9}$ & \\
\hline$p$-Benzoquinone $\mathrm{e}^{0 /-}$ & 1.47 & 1.375 & 1.385 & 4490 & 429 & $9.6 \times 10^{8}$ & $3.8 \times 10^{8}$ \\
\hline $\mathrm{TCNQ}^{0 /-}$ & 1.73 & 1.344 & 1.349 & 5250 & 516 & $4.1 \times 10^{9}$ & $4.0 \times 10^{9}$ \\
\hline Tetracyanoethylene $\mathrm{e}^{0 /-}$ & 1.97 & 1.301 & 1.291 & 6420 & 619 & $8.2 \times 10^{9}$ & $2.0 \times 10^{9}$ \\
\hline Benzonitrile $\mathrm{e}^{0 /-}$ & 1.59 & 1.374 & & 4450 & & $2.6 \times 10^{9}$ & $5.5 \times 10^{8}$ \\
\hline $\mathrm{TMPPD}^{+/ 0}$ & 1.375 & 1.387 & 1.400 & 4080 & 405 & $4.4 \times 10^{8}$ & $1.1 \times 10^{9}$ \\
\hline $\mathrm{PPD}^{+/ 0}$ & 1.375 & 1.383 & 1.391 & 4030 & 392 & $5.9 \times 10^{9}$ & $3.1 \times 10^{8}$ \\
\hline Ferrocene $^{+/ 0}$ & 1 & & $1.65^{\mathrm{d}}$ & & $1700^{\mathrm{d}}$ & $2.0 \times 10^{6 \mathrm{e}}$ & $7.5 \times 10^{6 \mathrm{f}}$ \\
\hline
\end{tabular}

a Average bond-order of the neutral and radical ion species.

${ }^{\mathrm{b}}$ Effective bond lengths and force constants of the reactants, calculated as the average of all the bonds of each reactant that contribute to the reaction coordinate.

${ }^{\mathrm{c}}$ Ref. [58].

d Distance from the metal to the center of the cyclopentadienyl ligand [59].

e The force constant was multiplied by $\sqrt{2}$ to account for the local-mode behavior of the Fe-cp bonds [60].

${ }^{f}$ Ref. [61].

oscillators. This can be done centering the two harmonic curves of the two reactants (products) around a single averaged equilibrium bond-length, constructed by averaging the equilibrium bondlengths of oxidized and reduced reactants (products) [32]

$l_{\mathrm{r}}=\frac{l_{\mathrm{red} 1}+l_{\mathrm{ox} 2}}{2} \quad l_{\mathrm{p}}=\frac{l_{\mathrm{ox} 1}+l_{\mathrm{red} 2}}{2}$

The same procedure is applied to the force constants

$f_{\mathrm{r}}=\frac{f_{\text {red } 1}+f_{\text {ox } 2}}{2} \quad f_{\mathrm{p}}=\frac{f_{\text {ox } 1}+f_{\text {red } 2}}{2}$

This reduction in the dimensionality of ET reactions leads to a formulation that is similar to that previously employed for bond-breaking-bondforming reactions. However, during the ET step, the bond orders are approximately maintained. For example, in naphthalene we have six single and five double bonds that participate in the reaction coordinate, i.e. an average bond order of 1.45 , whereas in naphthalene ${ }^{--}$we have a bond order of 1.41 because the extra electron occupies an anti-bonding orbital. Thus, this system is characterized by $n^{*}=1.43$. The bond lengths and force constants needed for the calculation of the naphthalene/naphthalene ${ }^{--}$electron exchange are the average of the corresponding values of the CC bonds. In fact, we only need data from the neutral species because the small increase in the bond lengths from the neutral to the anion is compensated by a concomitant decrease in the force constants. Table 6 presents the data needed to calculate the ET activation energies of the organic species discussed in this work.

At the TS, a fully extended (or compressed) bond of a reactant may reverse its motion and start its contraction (or extension), or may change to the product potential-energy curve where it may pursue its extension (or contraction). With this reversibility of the motion at the TS, the classical turning points of vibration of the reactant species are in quasi-equilibrium with respect to changes in the electric charges of the reactive system. Thus, we may apply equilibrium conditions to the activated complexes of an ET reaction and formulate the rate of passage through the activated complex configuration in terms of the 


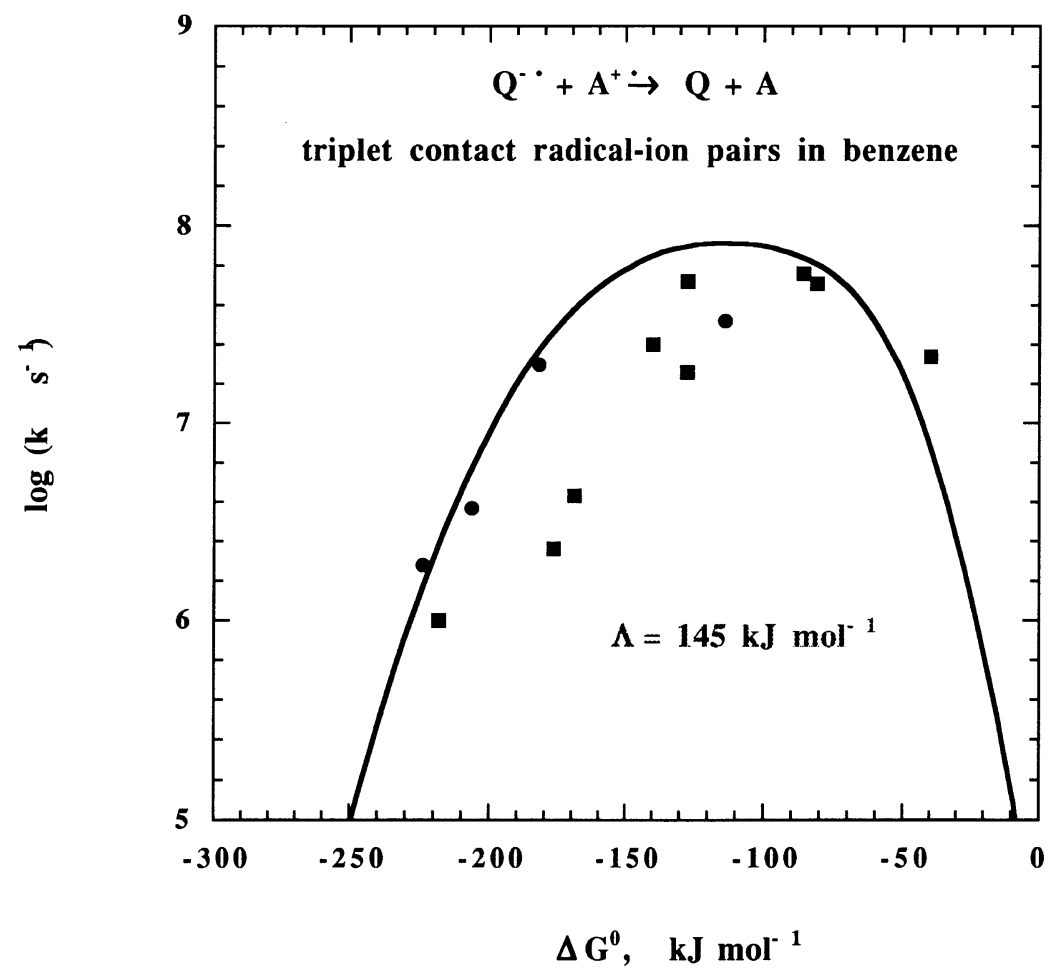

Fig. 8. Free-energy dependence of back-ET between quinone radical anions and radical cations forming ion pairs in benzene [40,58]. The CRIP were formed by the quenching of the triplet state of the quinones by electron donors, and the back-ET rates were calculated with a spinforbidden factor $\chi=2 \times 10^{-5}[58]$.

transition-state equation

$k_{\mathrm{et}}=\nu C^{1-b} \exp \left(-\frac{\Delta G^{\ddagger}}{\mathrm{R} T}\right)$

where $\nu$ is the frequency of conversion of the TS into products. For adiabatic reactions this is the vibrational frequency of the reactive modes which, for organic species, is $\nu \approx 10^{13} \mathrm{~s}^{-1}$.

The analogy between the treatment of bondbreaking-bond-forming and ET reactions suggests that Eq. (17) should also be a good coordinate for ET reactions. For self-exchanges it leads to the "intrinsic" energy barrier

$\Delta G_{0}^{\ddagger}=\frac{1}{2} \frac{f_{\text {ox }}+f_{\text {red }}}{2}\left[\frac{a^{\prime} \ln (2)}{2 n^{\ddagger}}\left(l_{\text {ox }}+l_{\text {red }}\right)\right]^{2}$

Table 6 shows some self-exchange rates calculated with Eqs. (22) and (23) using $\nu=10^{13} \mathrm{~s}^{-1}$. The absolute rates calculated with ISM are in reasonable agreement with the experimental ones. The $\mathrm{O}_{2} / \mathrm{O}_{2}^{--}$self- exchange involves a transition between $\mathrm{X}^{3} \Sigma_{\mathrm{g}}^{-}$and $\mathrm{X}^{2} \Pi_{\mathrm{g}}$ states that may have a symmetry/spin forbidden factor. The adiabatic rate calculated with ISM is $1.5 \times 10^{10} \mathrm{M}^{-1} \mathrm{~s}^{-1}$. This is a factor of $3.3 \times 10^{7}$ larger than the experimental value, and suggests the existence of a forbidden factor of $2 \times 10^{-4}$ per redox center. Endicott and co-workers inferred from their experimental studies that electron exchanges involving $\left.\left({ }^{4} \mathrm{~T}_{2}\right) \mathrm{Co}(\mathrm{II}) / /^{1} \mathrm{~A}_{1}\right) \mathrm{Co}(\mathrm{III})$ complexes have electronic retardation factors in the $10^{-3}-10^{-4}$ range $[33,34]$. Temperature dependence studies of the $\mathrm{O}_{2} /$ $\mathrm{O}_{2}^{--}$self-exchange may help to reveal the nonadiabatic nature of this exchange.

Based on the cross-relation expressed by Eq. (14), Marcus predicted that ET rates should increase with the exothermicity of the reactions, reach a maximum at $\Delta G^{0}=4 G_{0}^{\ddagger}$ and then decrease [35]. The overall free-energy profile of the ET rate should resemble an inverted parabola. The range of $\Delta G^{0}$ where the ET rates decrease with an increase in the reaction 


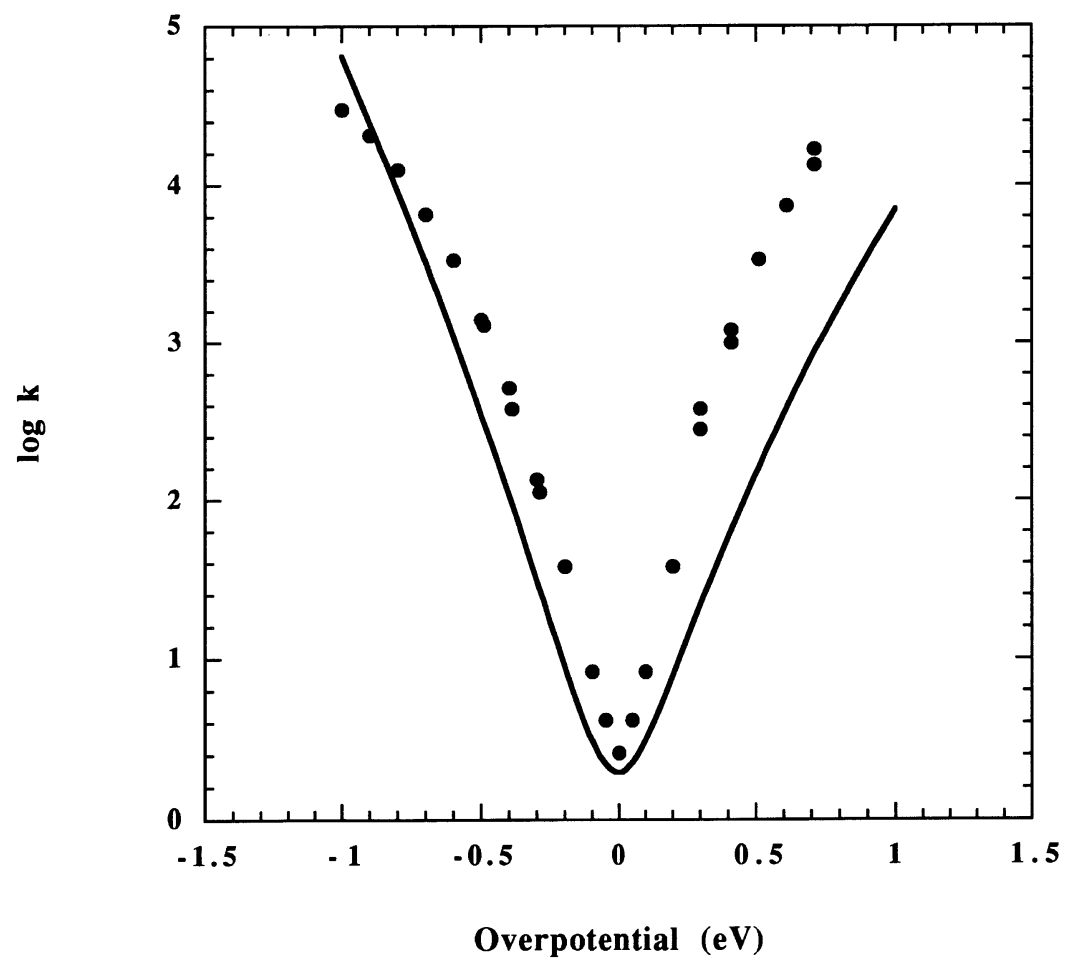

Fig. 9. Calculated and experimental Tafel plots for first-order heterogenous ET rates at gold electrodes covered by $n$-alkyl thiol monolayers terminated by a ferrocene derivative [44].

exothermicity is known as Marcus inverted region. For many years, the experimental studies of very exothermic photoinduced ET reactions did not show any evidence for the inverted behavior. Instead photoinduced ET rates approached the limit of diffusion at $\Delta G^{0} \approx-40 \mathrm{~kJ} \mathrm{~mol}^{-1}$, and remained controlled by diffusion for more negative values of $\Delta G^{0}$ [36]. It was only 26 years later that Closs and Miller provided the first clear evidence for an inverted region in intramolecular charge-shift reactions [37]. Shortly after similar observations were made in related intramolecular ETs and in back-ETs occurring in contact radical ions pairs (CRIP) [38-40]. Back-ETs in CRIPs formed in the quenching of triplet states are particularly convenient to follow experimentally because they are slowed by spin-forbidden factors and the quantum yield of back-ET is unity in apolar solvents. Fig. 8 illustrates the application of ISM to back-ETs between quinones ${ }^{--}$and amines $^{-+}$in benzene, using the data for $p$-benzoquinone and benzene shown in Table 6 and $\Lambda=145 \mathrm{~kJ} \mathrm{~mol}^{-1}$.
According to Eq. (16) we should have $\Lambda_{0}=$ $107 \mathrm{~kJ} \mathrm{~mol}^{-1}$ for these reactions. The inverted region calculated with $\Lambda_{0}$ starts at less exothermic free energies. As the value of $\Lambda$ increases, the inverted region becomes less pronounced and eventually a diffusioncontrolled plateau over a large range of $\Delta G^{0}$ is calculated for $\Lambda \approx 200 \mathrm{~kJ} \mathrm{~mol}^{-1}$. The displacement of the inverted region towards more negative $\Delta G^{0}$ values as the polarity of the solvent increases, is consistent with the behavior $\Lambda$ with the polarity of the media, discussed in the context of PT reactions. For still larger values of $\Lambda$, ISM predicts that $\Delta G^{0}$-dependence of the ET rates should go through a maximum, followed by a minimum and then a new maximum. Experimental evidence supporting this behavior was recently presented [32].

Heterogeneous ET reactions follow the same general principles of the homogenous ETs. However, the response of the metal electrode to the exchange of an electron with the redox partner does not involve energy changes. Thus, the intrinsic barrier of a species 
undergoing heterogenous ET is half of its intrinsic barrier in solution, as shown by Marcus $[41,42]$.

It was shown that $n$-alkyl thiols spontaneously adsorb on gold electrodes from dilute solution to form a monolayer coverage of the electrode [43]. When the other end of the alkyl chain is covalently linked to a redox species, it is possible to measure first-order rates for the tunneling of the electron from the redox species, across the monolayer, to the electrode, and vice-versa [44]. These rates are free from diffusion limitations and, for long alkyl chains, have negligible double layer effects. Further, very large overpotentials became experimentally accessible. Thus, they are particularly convenient to test the predictions of theoretical models.

Electron tunneling across long insulators reduced the effective reaction frequency from the value used before $\left(10^{13} \mathrm{~s}^{-1}\right)$ to much lower values. We estimate this frequency as the product between the electronic frequency in the donor $\left(\nu_{\mathrm{el}}=10^{15} \mathrm{~s}^{-1}\right)$ and the electron tunneling probability $\chi$. This probability can be estimated from the permeability of a square barrier of height $\Phi$ and width $r$ to an electron of mass $m_{\mathrm{e}}$,

$\chi_{\mathrm{r}}=\exp \left(-\frac{2}{\hbar} \sqrt{2 m_{\mathrm{e}} \Phi} r\right)$

We have shown that $\Phi=\Phi_{0} / n_{\mathrm{D}}^{2}$, where $\Phi_{0}$ is the absolute potential of the electron donor and $n_{\mathrm{D}}$ the refractive index of the barrier [45]. The width of the barrier for the system ferrocene $\mathrm{CO}_{2}-\left(\mathrm{CH}_{2}\right)_{16}-\mathrm{SH}-\mathrm{Au}$ is the edge-to-edge distance between ferrocene and the sulfur atom. We estimate it to be $r \approx 19 \AA$, from the distance of closest approach of the ferrocene group to the electrode, $\approx 20 \AA$ [44]. We describe the monolayer with $n_{\mathrm{D}}=1.6$. The absolute potential of ferrocene is $\Phi_{0}=5.17 \mathrm{eV}$.

In a metal electrode there is a continuum of donor or acceptor levels that is involved in ET. Thus, the overall rate is the integration over the energy accessible of the rates of each energy level. This can be written

$k_{\mathrm{HET}}=\nu_{\mathrm{el}} \rho_{\mathrm{F}} \mathrm{R} T \int \chi_{\mathrm{r}} f(\epsilon) \exp \left(-\frac{\epsilon^{\ddagger}}{\mathrm{k}_{\mathrm{B}} T}\right) \mathrm{d}\left(\frac{\epsilon}{\mathrm{k}_{\mathrm{B}} T}\right)$

where the density of states of the metal was assumed constant $\left(\rho_{\mathrm{F}}=0.27\right.$ for Au). The Fermi-Dirac distributions are, for the reduction and the oxidation processes,

$$
\begin{aligned}
& f_{\text {red }}(\epsilon)=\frac{1}{1+\exp \left(\epsilon / \mathrm{k}_{\mathrm{B}} T\right)} \\
& f_{\text {ox }}(\epsilon)=\frac{\exp \left(\epsilon / \mathrm{k}_{\mathrm{B}} T\right)}{1+\exp \left(\epsilon / \mathrm{k}_{\mathrm{B}} T\right)}
\end{aligned}
$$

In Fig. 9 we show the application of ISM to the heterogeneous ET in the system ferrocene $\mathrm{CO}_{2}-$ $\left(\mathrm{CH}_{2}\right)_{16}-\mathrm{SH}-\mathrm{Au}$ using the parameters presented in Table 6 for ferrocene, calculating $d$ with Eq. (17) with $\Lambda_{0}=340 \mathrm{~kJ} \mathrm{~mol}^{-1}$ from Eq. (16). These reactions are not very sensitive to reasonable changes in $\Lambda$. The free-energy of activation calculated for heterogenous ET is half that calculated for electron exchange between two redox species in solution. There are no adjustable parameters in this calculation. The curved rate constant dependence on the overpotential $(\eta)$ contrasts with the linear prediction of the Tafel equation $\eta=a+b \log (i)$, where $a$ and $b$ are constants and $i$ is the current intensity, that should be observed if Butler-Volmer kinetics were followed [46]. The curvature experimentally observed in consistent with ISM calculations, but the calculated asymmetry overestimates the observed one.

\section{Conclusions}

The application of ISM to many different types of chemical reactions provides a simple understanding of how the molecular structure of the reactants affects their reactivity. The major factors revealed by ISM are the influence of the reaction energy, the hypervalency at the TS, the force constants of the reactive bonds and the corresponding bond lengths. In ETs one must also consider the influence of nonadiabatic effects, either due to the distance between electron donor and acceptor of to spin changes.

\section{Acknowledgements}

We thank Praxis XXI (European Union) for financial support (Project no. Praxis/PCEX/C/QUI/108/ 96). 


\section{References}

[1] H.S. Johnston, C. Parr, J. Am. Chem. Soc. 85 (1963) 2544.

[2] L. Pauling, J. Am. Chem. Soc. 69 (1947) 542.

[3] A.A.C.C. Pais, L.G. Arnaut, S.J. Formosinho, J. Chem. Soc. Perkin Trans. 2 (1998) 2577.

[4] J.A. Kerr, in: C.H. Bamford, C.F.H. Tipper (Eds.), Selected Elementary Reactions, vol. 18, Elsevier, Amsterdam, 1975, pp. 99-109.

[5] B.C. Garrett, D.G. Truhlar, A.J.C. Varandas, N.C. Blais, Int. J. Chem. Kinet. 18 (1986) 1065.

[6] D.M. Camaioni, S.T. Autray, T.B. Salinas, J.A. Franz, J. Am. Chem. Soc. 118 (1996) 2013.

[7] G.S. Hammond, J. Am. Chem. Soc. 77 (1955) 334.

[8] M.G. Evans, M. Polanyi, Trans. Faraday Soc. 34 (1938) 11.

[9] A.J.C. Varandas, S.J. Formosinho, J. Chem. Soc., Faraday Trans. 282 (1986) 953.

[10] D.L. Baulch, C.J. Cobos, R.A. Cox, C. Esser, P. Frank, T. Just, J.A. Kerr, M.J. Pilling, J. Troe, R.W. Walker, J. Warnatz, J. Phys. Chem. Ref. Data 21 (1992) 411.

[11] S. Hoz, H. Basch, J.L. Wolk, T. Hoz, E. Rozental, J. Am. Chem. Soc. 121 (1999) 7724.

[12] M.W. Schmidt, K.K. Baldridge, J.A. Boatz, S.T. Elbert, M.S. Gordon, J.H. Jensen, S. Koseki, N. Matsunaga, K.A. Nguyen, S.J. Su, T.L. Windus, M. Dupuis, J.A. Montgomery, J. Comput. Chem. 14 (1993) 1347.

[13] A.J. Gordon, R.A. Ford, The Chemist's Companion, Wiley, New York, 1972 (pp. 107-114).

[14] S.J. Formosinho, J. Chem. Soc., Perkin Trans. 2 (1987) 61.

[15] L.G. Arnaut, S.J. Formosinho, J. Phys. Chem. 92 (1988) 685.

[16] L.G. Arnaut, S.J. Formosinho, J. Phys. Org. Chem. 3 (1990) 95.

[17] L.G. Arnaut, J. Phys. Org. Chem. 4 (1991) 726.

[18] A. Streitwieser Jr., F. Guibé, J. Am. Chem. Soc. 100 (1978) 4532.

[19] M.-L. Ahrens, G. Maass, Angew. Chem. Int. Ed. 7 (1968) 818.

[20] J. Wirz, Pure Appl. Chem. 70 (1998) 2221.

[21] A.O. Cohen, R.A. Marcus, J. Phys. Chem. 72 (1968) 4249.

[22] N. Agmon, R.D. Levine, Chem. Phys. Lett. 52 (1977) 197.

[23] N. Agmon, Int. J. Chem. Kinet. 13 (1981) 333.

[24] S.J. Formosinho, in: S.J. Formosinho, I.G. Csizmadia, L.G. Arnaut (Eds.), Theoretical and Computational Models for Organic Chemistry, NATO ASIKluwer, Dordrecht, 1991, p. 159.

[25] C.F. Bernasconi, R.D. Bunnel, Isr. J. Chem. 26 (1985) 420.

[26] R.A. Marcus, J. Chem. Phys. 24 (1956) 966.

[27] J. Lind, X. Shen, G. Merényí, B.O. Jonsson, J. Am. Chem. Soc. 111 (1989) 7654.

[28] H. Kojima, A.J. Bard, J. Am. Chem. Soc. 97 (1975) 6317.

[29] S. Fukuzumi, I. Nakanishi, T. Suenobu, K.M. Kadish, J. Am. Chem. Soc. 121 (1999) 3468.

[30] S. Jakobsen, K.V. Mikkelsen, S.U. Pedersen, J. Phys. Chem. 100 (1996) 7411.

[31] K. Zahir, J.H. Espenson, A. Bakac, J. Am. Chem. Soc. 110 (1988) 5059.
[32] S.J. Formosinho, L.G. Arnaut, R. Fausto, Prog. React. Kinet. 23 (1998) 1.

[33] T. Buranda, Y. Lei, J.F. Endicott, J. Am. Chem. Soc. 114 (1992) 6916.

[34] X. Song, Y. Lei, S. Van Wallendal, M.W. Perkovic, D.C. Jackman, J.F. Endicott, D.P. Rillema, J. Phys. Chem. 97 (1993) 3225.

[35] R.A. Marcus, Faraday Discuss. Chem. Soc. 29 (1960) 21.

[36] D. Rehm, A. Weller, Isr. J. Chem. 8 (1970) 259.

[37] G.L. Closs, L.T. Calcaterra, N.J. Green, K.W. Penfield, J.R. Miller, J. Phys. Chem. 90 (1986) 3673.

[38] I.R. Gould, D. Ege, S.L. Mattes, S. Farid, J. Am. Chem. Soc. 109 (1987) 3794.

[39] E. Vauthey, P. Suppan, E. Haselbach, Helv. Chim. Acta 71 (1988) 93.

[40] P.P. Levin, P.F. Pluzhnikov, V.A. Kuzmin, Chem. Phys. Lett. 147 (1988) 283.

[41] R.A. Marcus, Can. J. Chem. 37 (1959) 155.

[42] R.A. Marcus, J. Phys. Chem. 67 (1963) 853.

[43] M.D. Porter, T.B. Bright, D.L. Allara, C.E.D. Chidsey, J. Am. Chem. Soc. 109 (1987) 3559.

[44] C.E.D. Chidsey, Science 251 (1991) 919.

[45] L.G. Arnaut, L.G. Formosinho, J. Photochem. Photobiol. A: Chem. 100 (1996) 15.

[46] A.J. Bard, L.R. Faulkner, Electrochemical Methods, Wiley, New York, 1980.

[47] NIST Standard Reference Database \# 69, February 2000.

[48] A.A. Zavitsas, C. Chatgilialoglu, J. Am. Chem. Soc. 117 (1995) 10645.

[49] D.F. McMillen, D.M. Golden, Annu. Rev. Phys. Chem. 33 (1982) 493.

[50] M.K. Dubey, R. Mohrschladt, N.M. Donahue, J.G. Anderson, J. Phys. Chem. A 101 (1997) 1494.

[51] B.P. Roberts, J. Chem. Soc. Perkin Trans. 2 (1996) 2719.

[52] M.R. Levy, Prog. React. Kinet. 10 (1979) 1.

[53] S.S. Shaik, H.B. Schlegel, S. Wolfe, Theoretical Aspects of Physical Organic Chemistry, Wiley, New York, 1991.

[54] S.E. Barlow, J.M. Van Doren, V.M. Bierbaum, J. Am. Chem. Soc. 110 (1988) 7240.

[55] A. Streitwieser Jr., P.H. Owens, G. Sonnischsen, W.K. Smith, G.R. Ziegler, H.M. Niemeyer, T.L. Kruger, J. Am. Chem. Soc. 95 (1973) 4254.

[56] J.E. Crooks, in: C.H. Bamford, C.F.H. Tipper (Eds.), Comprehensive Chemical Kinetics, Elsevier, Amsterdam, 1977, p. 197.

[57] Z. Luz, S. Meiboom, J. Am. Chem. Soc. 86 (1964) 4766.

[58] C.C. Soares, L.G. Arnaut, submitted for publication.

[59] T.N. Doman, C.R. Landis, B. Bosnich, J. Am. Chem. Soc. 114 (1992) 7264.

[60] S.J. Formosinho, L.G. Arnaut, J. Mol. Struct. (Theochem.) 130 (1994) 105.

[61] R.M. Nielson, G.E. McManis, L.K. Safford, M.J. Weaver, J. Phys. Chem. 93 (1989) 2152.

[62] E. Kraka, J. Gauss, D. Cremer, J. Chem. Phys. 99 (1993) 5306.

[63] A. Goumri, W.-J. Yuan, L. Ding, Y. Shi, P. Marshall, Chem. Phys. 177 (1993) 233.

[64] P.W. Seakins, M.J. Pilling, J. Phys. Chem. 95 (1991) 9878. 